\title{
Prevalence of National Responsiveness to HBV Vaccine After 22 Years of Iranian Expanded Program on Immunization (EPI): A Systematic Review and Meta-Analysis Study
}

\author{
Reza Rezaee ${ }^{1}$; Bahman Aghcheli ${ }^{2}$; Vahdat Poortahmasebi ${ }^{2}$; Mostafa Qorbani ${ }^{3,4}$; Seyed Moayed \\ Alavian ${ }^{5}$; Seyed Mohammad Jazayeri ${ }^{2, *}$ \\ ${ }_{2}^{1}$ Ministry of Health and Medical Education, Deputy of Curative Affairs, Budget Administration, Tehran, IR Iran \\ ${ }_{3}^{2}$ Hepatitis B Molecular Laboratory, Department of Virology, School of Public Health, Tehran University of Medical Sciences, Tehran, IR Iran \\ ${ }^{3}$ Department of Community Medicine, Alborz University of Medical Sciences, Karaj, IR Iran \\ ${ }_{5}^{4}$ Non-Communicable Disease Research Center, Endocrinology and Metabolism Population Sciences Institute, Tehran University of Medical Sciences, Tehran, IR Iran \\ ${ }^{5}$ Middle East Liver Diseases Center (MELD Center), Tehran, IR Iran \\ ${ }^{*}$ Corresponding Author: Seyed Mohammad Jazayeri, Hepatitis B Molecular Laboratory, Department of Virology, School of Public Health, Tehran University of Medical Sciences, P. O. \\ Box: 15155-6446, Tehran, IR Iran. Tel: +98-2188992660, E-mail: jazayerism@tums.ac.ir
}

Received: September 14, 2014; Revised: December 16, 2014; Accepted: March 29, 2015

\begin{abstract}
Context: Hepatitis B Virus expanded program on immunization (EPI) started on 1993 in Iran. Most surveys have assessed the level of response to vaccine by measuring the titers of anti-HBs. This meta- analysis aimed to summarize the Iranian published data on the rate of vaccine-responders versus non-responders. Moreover, the impact of variables such as age, gender, type of vaccine, etc. on the levels of responsiveness was evaluated.

Evidence Acquisition: All published papers on this topic in Iranian and international journals with affiliation of "Iran" were reviewed using standard keywords up to 2014. We included our study to healthy participants with no previous HBV infection and who had already received a complete course of $\mathrm{HB}$ vaccine. The estimated prevalence and $95 \%$ confidence intervals in 28 eligible articles for HBV vaccine responders (anti-HBs $>10 \mathrm{IU} / \mathrm{mL}$ ) and non-responders $(10<$ ) were analyzed by random effect method due to between-study heterogeneity. Results: The age of subjects was between 6 months and 15 years old. Overall, 5991 (51.5\%) were male and 4571 (48.5\%) females. Overall, 80\% were responders to vaccine versus $20 \%$ nonresponders. With increase in age, the number of responders to vaccine decreased significantly $(\mathrm{P}=0.001)$. There was no strong difference between responders versus nonresponders to vaccine for gender, types of vaccine, ethnicity and living area.

Conclusions: The results arose from this meta-analysis highlighted the safety of vaccine and its effectiveness in stimulating immune response of vaccines, despite being different in generation, manufacturers and types. Moreover, there was no substantial difference between Iranian and other international investigations in the rate of nonresponsiveness to HBV vaccine.
\end{abstract}

Keywords: HBV Vaccine; Anti-HBs; Expanded Program on Vaccination; Responder; Nonresponder

\section{Context}

Most clinical complications associated with hepatitis $\mathrm{B}$ are manifested in conditions, particularly cirrhosis and hepatocellular carcinoma (HCC) as consequences of chronic infection. Hepatocellular carcinoma (HCC) is the sixth most common in the world and the third leading cause of cancer-related death (1). An effective vaccine has been available for more than two decades, which has decreased the prevalence of HBV infection worldwide dramatically. The primary goal of hepatitis B prevention is reduction of chronic HBV infection and HBV-related chronic liver disease. A secondary goal is prevention of acute hepatitis B. In 1991, the World Health Organization recommended that all countries include hepatitis vaccine in their routine infant immunization program, especially in areas where hepatitis B is endemic (2). The global reported decline in HBsAg prevalence, especially from HBV endemic area (such as South East Asia, Alaska, etc.) has been come as something of a surprise. This falling off has been discussed in depth elsewhere (3). Naively speaking, one would expect that the ultimate decline is reaching; however, this is not the case; universally, about $5-20 \%$ of vaccine failure among recipients has been reported manifested by different levels of hypo- or nonresponsiveness to HBV vaccination $(4,5)$. Historically, the potency of immune response after immunization against hepatitis B has been assessed by measuring antibody to HBsAg. The persistence of antiHBs above the protection level $(>10 \mathrm{IU} / \mathrm{mL})$ in vaccine recipient is the main goal. This persistence declines by age, particularly, during the first years after vaccination (6). On the other hand, a growing body of literature has shown that HBV vaccine-induced immunologic memory lasting persists more than 15 years after immunization $(7,8)$.

Copyright ( 2015, Kowsar Corp. This is an open-access article distributed under the terms of the Creative Commons Attribution-NonCommercial 4.0 International License (http://creativecommons.org/licenses/by-nc/4.0/) which permits copy and redistribute the material just in noncommercial usages, provided the original work is properly cited. 
In 1989, Iranian Ministry of Health launched an immunization program in four provinces as a pilot plan. Subsequently, in 1993, the immunization was extended to all provinces. This has led to $98 \%$ coverage of all infants nationally. Afterwards, many researches conducted on the level of response to HBV vaccine among Iranian children and ample data on the coverage rate of vaccine together with evaluation of vaccine responsiveness published in Iran so far. In this study, a systematic review and metaanalysis was performed to provide the statistic power on investigations performed nationally and to provide a summary of the results.

\section{Evidence Acquisition}

We performed a comprehensive search on PubMed, ISI, Scopus, Iran Medex and Scientific Information Database (SID), on published describing anti-HBs levels in children below15 years (after six months to 15 years old) who received three doses of HBV vaccine following EPI. All published data from 1994 to August 2014 included in this review.

\subsection{Outcomes of Interest and Definitions}

The primary outcome was frequency of persons with protective levels of anti-HBs (>10 IU/mL) following HBV vaccination. The secondary outcome was frequency of nonresponders to $\mathrm{HBV}$ vaccine $(<10 \mathrm{IU} / \mathrm{mL})$.

\subsection{Inclusion and Exclusion Criteria and Date Ex- traction}

The main inclusion criterion was all studies that included subjects under 15 years old who received 3 doses of HBV vaccine (regardless of type and brand of vaccines). We limited our investigation to apparently healthy participants and no previous HBV infection. We excluded all studies in which individuals received vaccine episodes out of vaccination schedule (less or more administrations) and in those with any medical interventions (such as using adjuvant, booster doses etc.). Moreover, we did not include surveys that investigated responsiveness to vaccine in those with medical conditions (children born to HBsAg positive mothers, thalassemia, dialysis, received $\mathrm{HB}$ vaccine plus immunoglobulin, predisposing factors for immunodeficiency such as HIV, etc.).

\subsection{Data Extraction}

Data was extracted from selected studies including the name of author, year of publication, the mean age of participants and the levels of anti-HBs in different case-studied. Subjects were divided into two categories: responders who showed anti-HBs levels $>10 \mathrm{IU} / \mathrm{mL}$ and nonresponders (anti-HBs $<10 \mathrm{IU} / \mathrm{mL}$ ). We merged the subjects who harbored levels between two extremes; 10 and $100 \mathrm{IU} / \mathrm{mL}$, as responders (because some studies assigned these levels as hypo-responsiveness). Age and genders of participants were analyzed. Number of HBsAg and anti-HBc positive cases also included in data analysis. The medical subject headings (Mesh) including Entry Terms of PubMed and Emtree of Scopus with affiliation to "Iran" for searching in English databases (HBV vaccine, Anti-HBs, Expanded program on vaccination, prevalence, responders and nonresponders) were used for conducting a more efficient search. Persian keywords equivalent to their English terms were used for searching in national search engines. The references of selected citations and non-published national surveys were hand-searched. The authors assessed the risk of bias in the included studies using a risk-of-bias tool. Any disagreements were resolved through discussion among the authors until a consensus was reached. Studies that had an adequate handling of incomplete outcome data, were free of selective reporting, included an adequate intervention description, had appropriate criteria for participant recruitment and included an adequate outcome explanation were considered low-bias risk trials. The studies with one or more unclear or inadequate quality component were considered high-bias risk trials.

\subsection{Statistical Analysis}

Data was collected according to a standard protocol independently by two authors. The authors were not blinded to the names of studies' authors, journals and results. Any disagreements were resolved through discussion among the authors until consensus was reached (Kappa coefficient: 78\%). Data are expressed as percentages for categorical variables and means and SDs (standard deviation) for continuous variables. Statistical heterogeneity of reported prevalence was explored by Chi-square $\left(\chi^{2}\right.$ or Chi2)-based Q-test and was regarded to be statistically significant at the $10 \%$ significance level $(P<0.10)$. To gain better insight into the prevalence of dyslipidemia and its heterogeneity throughout Iran, we analyzed our findings using random-effects model with a 95\% confidence interval (CI). We also used the I2 statistic to quantify inconsistency in results between the studies. The analyses were conducted with STATA software, version 11.0, Produced by StataCorp, the USA.

\section{Results}

Twenty-eight eligible articles were found in the literature review, all were potentially related to the Iranian EPI. Table 1 shows summary of Iranian studies on immunization program. In total, these investigations were performed on 11639 children who received full three doses of vaccine. The age of subjects was between 6 months and 15 years old with the mean age of $5.21 \pm 3.64$ years. Overall, 5991 were male (51.5\%) and 4571 females (48.5\%). Overall, 9311 (80\%) responded to vaccine (anti-HBs $>10 \mathrm{IU} / \mathrm{mL}$ ). On the other hand, 2328 (20\%) were nonresponders (anti-HBs $<10 \mathrm{IU} / \mathrm{mL}$ ). The mean titers of antibody for responders and non-responders were $287.05 \pm 332.80 \mathrm{IU} / \mathrm{mL}$ and 4.08 $\pm 1.70 \mathrm{IU} / \mathrm{mL}$, respectively which was statistically signifi- 
Rezaee R et al.

cant $(\mathrm{P}=0.024)$. Among responders, the mean anti-HBs titers showed differences between a cut-off of three years old; $500.95 \pm 484.19$ and $164.82 \pm 139.44 \mathrm{IU} / \mathrm{mL}$ for those who were under 3 years old versus children more than 3 years old. However, this issue did not reach statistically significant $(\mathrm{P}=0.109)$.

\begin{tabular}{|c|c|c|c|c|c|c|c|}
\hline Author (s) & $\begin{array}{c}\text { No. of } \\
\text { Samples }\end{array}$ & Region & Mean Age, y & Type of Vaccine & HBsAg & Anti-HBc & $\begin{array}{c}\text { Prevalence of } \\
\text { Responsiveness }^{a}\end{array}$ \\
\hline Saffar et al. (9) & & Mazandaran & $10-11$ & Engerix - B & $\mathrm{NI}$ & $\mathrm{NI}$ & $262(57.8)$ \\
\hline $\mathrm{T}$ & 453 & & & & & & \\
\hline Behjati et al. (10) & & Yazd & 8 & $\mathrm{NI}$ & $\mathrm{NI}$ & $\mathrm{NI}$ & \\
\hline $\mathrm{T}^{\mathrm{b}}$ & 200 & & & & & & 69 \\
\hline M & 100 & & & & & & 71 \\
\hline $\mathrm{F}$ & 100 & & & & & & 76 \\
\hline Taghavi Ardakani et al.(11) & & Isfahan & 14 & $\mathrm{NI}$ & 0 & $4 \%$ & \\
\hline $\mathrm{T}$ & 200 & & & & & & 93.5 \\
\hline M & 100 & & & & & & 95 \\
\hline $\mathrm{F}$ & 100 & & & & & & 92 \\
\hline Hadi et al. (12) & & Fars & $6-9$ & $\mathrm{NI}$ & $\mathrm{NI}$ & $\mathrm{NI}$ & \\
\hline $\mathrm{T}$ & 374 & & & & & & 65.6 \\
\hline M & 196 & & & & & & 66.3 \\
\hline $\mathrm{F}$ & 178 & & & & & & 64.5 \\
\hline Jafarzadeh et al.(13) & & Kerman & $10-11$ & Engerix - B GSK & $\mathrm{NI}$ & $11(7.5)$ & \\
\hline $\mathrm{T}$ & 146 & & & & & & 47.9 \\
\hline M & 58 & & & & & & 46.6 \\
\hline $\mathrm{F}$ & 88 & & & & & & 48.9 \\
\hline Afsharian et al. (14) & & Kermanshah & $6-7$ & $\mathrm{NI}$ & $\mathrm{NI}$ & $\mathrm{NI}$ & \\
\hline $\mathrm{T}$ & 196 & & & & & & 69.3 \\
\hline M & 98 & & & & & & 28.6 \\
\hline $\mathrm{F}$ & 98 & & & & & & 71.4 \\
\hline Yazdanpanah et al. (15) & & Kohgiloyeh and Boyerahmad & $5-7$ & Recombivax - HB & 0 & $\mathrm{NI}$ & \\
\hline $\mathrm{T}$ & 729 & & & & & & 84.4 \\
\hline M & 425 & & & & & & 83.8 \\
\hline $\mathrm{F}$ & 304 & & & & & & 85.2 \\
\hline Mahyar (16) & & Qazvin & 6 & $\mathrm{NI}$ & $\mathrm{NI}$ & $\mathrm{NI}$ & \\
\hline $\mathrm{T}$ & 40 & & & & & & 87.5 \\
\hline M & 20 & & & & & & 89 \\
\hline $\mathrm{F}$ & 20 & & & & & & 83 \\
\hline Rafizade et al.(17) & & Zanjan & $7-9$ & $\mathrm{NI}$ & $\mathrm{NI}$ & $3(1)$ & \\
\hline $\mathrm{T}$ & 273 & & & & & & 48 \\
\hline Mostafavi Zadeh (18) & & Charmahal Bakhtiari & $5-6$ & $\mathrm{NI}$ & $\mathrm{NI}$ & $\mathrm{NI}$ & \\
\hline $\mathrm{T}$ & 394 & & & & & & 64 \\
\hline M & 211 & & & & & & 61 \\
\hline $\mathrm{F}$ & 183 & & & & & & 67.8 \\
\hline Esmaili et al.(19) & & Mazandaran & $<7$ & $\mathrm{NI}$ & $\mathrm{NI}$ & $\mathrm{NI}$ & \\
\hline $\mathrm{T}$ & 97 & & & & & & 87.6 \\
\hline M & 52 & & & & & & 86.54 \\
\hline $\mathrm{F}$ & 45 & & & & & & 88.9 \\
\hline Jazayeri,(Unpublished) & & Alborz & $9-15$ & Heber biovac & 0 & 0 & \\
\hline $\mathrm{T}$ & 821 & & & & & & 51.6 \\
\hline M & 423 & & & & & & 53.2 \\
\hline $\mathrm{F}$ & 398 & & & & & & 50 \\
\hline Shamsizadeh et al. (20) & & Khoozestan & 6 & Cuban Vaccine & $\mathrm{NI}$ & $\mathrm{NI}$ & \\
\hline $\mathrm{T}$ & 427 & & & & & & 75.4 \\
\hline M & 204 & & & & & & 70.1 \\
\hline $\mathrm{F}$ & 223 & & & & & & 80.3 \\
\hline Hosseini et al. (21) & & Tehran & $1.5-5$ & $\mathrm{NI}$ & 0 & & \\
\hline $\mathrm{T}$ & 165 & & & & & & 91 \\
\hline Salehi et al. (22) & & $\begin{array}{c}\text { Isfahan - Lorestan - Charma- } \\
\text { hal Bakhtiari }\end{array}$ & $5.5-6$ & Recombivax & $\mathrm{NI}$ & $\mathrm{NI}$ & \\
\hline
\end{tabular}


Rezaee R et al.

\begin{tabular}{|c|c|c|c|c|c|c|c|}
\hline $\mathrm{T}$ & 3758 & & & & & & 80.7 \\
\hline M & 2456 & & & & & & 79.2 \\
\hline $\mathrm{F}$ & 1302 & & & & & & 83.5 \\
\hline Ahmadi et al. (23) & & Hormozgan & $\begin{array}{c}12-15 \mathrm{mo}, 21- \\
24 \mathrm{mo}\end{array}$ & $\mathrm{NI}$ & $\mathrm{NI}$ & $\mathrm{NI}$ & \\
\hline $\mathrm{T}$ & 186 & & & & & & 87 \\
\hline Kazemi et al. (24) & & Zanjan & $1-4$ & NI & 0 & 0 & \\
\hline $\mathrm{T}$ & 100 & & & & & & 98 \\
\hline M & 58 & & & & & & 97 \\
\hline $\mathrm{F}$ & 42 & & & & & & 42 \\
\hline Azarkar (25) & & Khorasan - Razavi & $12-16 \mathrm{mo}$ & Eberbiovac & $\begin{array}{l}\text { Khorasan- } \\
\text { Razavi }\end{array}$ & $12-16 \mathrm{mo}$ & \\
\hline $\mathrm{T}$ & 100 & & & & & & 81 \\
\hline M & 50 & & & & & & 80 \\
\hline $\mathrm{F}$ & 50 & & & & & & 82 \\
\hline Dahifar (26) & & NI & $15-45 \mathrm{mo}$ & Herberbiovac & $\mathrm{NI}$ & 0 & \\
\hline $\mathrm{T}$ & 538 & & & & & & 84.4 \\
\hline M & 294 & & & & & & 82 \\
\hline $\mathrm{F}$ & 244 & & & & & & 87.5 \\
\hline Jafarzadeh et al. (27) & & Kerman & Neonate & Herberbiovac & $3(1.29)$ & $6(2.59)$ & \\
\hline $\mathrm{T}$ & 231 & & & & & & 96.1 \\
\hline M & 113 & & & & & & 94.7 \\
\hline $\mathrm{F}$ & 118 & & & & & & 97.5 \\
\hline Fatolah Poor et al. (28) & & Kordistan & $1-2$ & NI & $\mathrm{NI}$ & NI & \\
\hline $\mathrm{T}$ & 225 & & & & & & 93.3 \\
\hline M & 121 & & & & & & 93.3 \\
\hline $\mathrm{F}$ & 104 & & & & & & 93.2 \\
\hline Salehi et al. (29) & & Sistan Baloochestan & $15-23 \mathrm{mo}$ & Herberbiovac & $\mathrm{NI}$ & NI & \\
\hline $\mathrm{T}$ & 324 & & & & & & 78.4 \\
\hline M & 174 & & & & & & 77 \\
\hline $\mathrm{F}$ & 150 & & & & & & 80 \\
\hline Jafarzadeh et al. (27) & & West Azerbayjan & Neonate & Herberbiovac & Neg & Neg & \\
\hline $\mathrm{T}$ & 290 & & & & & & 98.3 \\
\hline M & 145 & & & & & & 98.6 \\
\hline $\mathrm{F}$ & 145 & & & & & & 97.9 \\
\hline Moradi (30) & & Golestan & 7-12 mo & $\begin{array}{c}\text { Euvax B, a Korean } \\
\text { HBV vaccine }\end{array}$ & $1(4.6)$ & $5(2.2)$ & \\
\hline $\mathrm{T}$ & 215 & & & & & & 86 \\
\hline M & 119 & & & & & & 84 \\
\hline $\mathrm{F}$ & 96 & & & & & & 89.9 \\
\hline Zamani et al. (31) & & Tehran & $12-24 \mathrm{mo}$ & Heber Biotec, & $\mathrm{NI}$ & $\mathrm{NI}$ & \\
\hline $\mathrm{T}$ & 115 & & & & & & 94.8 \\
\hline M & 62 & & & & & & 93.5 \\
\hline $\mathrm{F}$ & 53 & & & & & & 96.2 \\
\hline Shokri et al. (32) & & Kerman & Neonate & Heberbiovac & $\mathrm{NI}$ & $\mathrm{NI}$ & \\
\hline $\mathrm{T}$ & 735 & & & & & & 95.2 \\
\hline M & 357 & & & & & & 94.1 \\
\hline $\mathrm{F}$ & 378 & & & & & & 96.2 \\
\hline Rostami et al. (33) & & Mazandaran & $15 \mathrm{mo}$ & Heber biovac & $\mathrm{NI}$ & NI & \\
\hline $\mathrm{T}$ & 97 & & & & & & 85.6 \\
\hline M & 50 & & & & & & 88 \\
\hline $\mathrm{F}$ & 47 & & & & & & 83 \\
\hline Rezaei et al. (34) & & Semnan & $1-15$ & Cuban Vaccine & $\mathrm{NI}$ & NI & \\
\hline $\mathrm{T}$ & 210 & & & & & & 79 \\
\hline M & 105 & & & & & & 78 \\
\hline $\mathrm{F}$ & 105 & & & & & & 80 \\
\hline
\end{tabular}


Rezaee R et al.

Meta-regression analysis showed that with increase in age, the number of responders to vaccine decreased significantly $(\mathrm{P}=0.001)$ (Table 2$)$. Put another way, the number of nonresponders to vaccine increased as age of vaccines increased $(\mathrm{P}<0.001)$. The other finding was that between years 1995 and 2014, there was no significant difference in the mean anti-HBs titers between studies $(\mathrm{P}=0.428)$.

The details of gender for responders versus nonresponders were missed in four articles. However, results from 24 publications indicated that of total 10562 children, 5070 (56.3\%) of males and 3937 (43.7\%) of females had antibody levels of $>10 \mathrm{IU} / \mathrm{mL}$. In contrast, 1346 (59.0\%) and 938 (41.0\%) of males and females had antibody levels of $<10 \mathrm{IU} / \mathrm{mL}$, respectively. Final result for meta-analysis and model performed for total estimated prevalence is shown in Table 3. However, there was no strong difference between responders versus nonresponders to vaccine ( $\mathrm{P}$ $=0.119$ ). Forest plot of prevalence of HBV vaccine responsiveness in Iranian general, male and female population is shown in Figures 1-3, respectively.
Despite some studies did not specify the type of vaccine used, using different vaccines (Heberbiovac, Cuba; Engerix-B, GSK; Recombivax, Cuba; Euvax B) with the same protocol for vaccine doses and administrations, did not show any significant differences regarding response rate to vaccine $(\mathrm{P}<0.001)$.

Only three studies contained the data on HBsAg prevalence between subjects. The rates ranged between 0 and $1.29 \%$ (Table 1). Furthermore, prevalence of anti-HBc was between 0 and $7.5 \%$ in different reports (Table 1 ).

In those studies which compared the rate of responsiveness to HBV vaccine between urban and rural area, no significant differences were found between responders and nonresponders (results not shown). No significant complications and side effects were reported after vaccine administration (results not shown).

Response to vaccine according to ethnic groups (Turkish, Arab, Kurdish, Turkmen, etc.) and geographic area was evaluated; however, no strong correlations were found (P 0.826 and 0.896 , respectively).

Table 2. Result of Meta-Regression Analysis

\begin{tabular}{lccr}
\hline Prevalence & Coefficient & Standard Error & CI 95\% \\
\hline Year & 0.0196224 & 0.056 & $-0.0005681-0.0398129$ \\
Mean age & -0.0457975 & 0.001 & $-.0682583-(-.00233366)$ \\
Type of vaccine & -0.0509606 & 0.162 & $-0.1261901-0.0242688$ \\
Constant & -38.23503 & 0.060 & $-78.49684-2.026786$ \\
\hline
\end{tabular}

Table 3. Final Result for Meta-analysis and Model Performed for Total Estimated Prevalence

\begin{tabular}{|c|c|c|c|c|c|c|}
\hline Variables & Number of Study & Prevalence, $\%$ & CI 95\% & Mode & I Square & Pvalue \\
\hline Total & 28 & 80 & $0.76-0.83$ & Random effect & 99.8 & $<0.001$ \\
\hline Male & 24 & 80 & $0.77-0.84$ & Random effect & 99.7 & $<0.001$ \\
\hline Female & 24 & 83 & 081-0.86 & Random effect & 99.6 & $<0.001$ \\
\hline
\end{tabular}

Table 4. Published Prevalence of Response to HBV Vaccine from Different Geographic Areas a

\begin{tabular}{|c|c|c|c|c|c|c|c|c|}
\hline Author(s) & Country & Number & Age, y & $\begin{array}{c}\text { No } \\
\text { Responder, \% }\end{array}$ & Responder, \% & $\begin{array}{c}\text { Association } \\
\text { With Age }\end{array}$ & $\begin{array}{c}\text { Association } \\
\text { With Gender }\end{array}$ & Pvalue \\
\hline Elian et al. (35) & Palestine & 180 & $2-11$ & 1.7 & 98.3 & Yes & No & $\leq 0.04$ \\
\hline Livramento et al. (36) & Brazil & 371 & $10-15^{b}$ & 50.1 & 49.9 & NI & NI & $\mathrm{NI}$ \\
\hline Madour et al. (37) & Libya & 277 & $1-12$ & 32.1 & 67.9 & Yes & No & 0.386 \\
\hline Zanetti et al. (38) & Italy & 1212 & $10.9^{C}$ & 36 & 64 & NI & No & 0.0001 \\
\hline Dong (39) & China & 5407 & $0-8$ & 35.46 & 64.54 & Yes & $\mathrm{NI}$ & $<0.05$ \\
\hline Sallam et al. (40) & Yemen & 170 & $13-73 \mathrm{mo}$ & 16.5 & 83.5 & No & $\mathrm{NI}$ & 0.4 \\
\hline Belloni et al. (41) & Italy & 1968 & $38 \mathrm{wk}$ & 2.5 & 97.5 & $\mathrm{NI}$ & NI & $<0.05$ \\
\hline Hwang et al. (42) & China & 100 & NI & 10 & 90 & Yes & NI & $\mathrm{NI}$ \\
\hline Chongsrisawat et al. (43) & Thailand & 2887 & $0.5-18$ & 58.4 & 41.6 & $\mathrm{NI}$ & NI & $\mathrm{NI}$ \\
\hline Sadeck et al. (44) & Brazil & 56 & $6-12 \mathrm{mo}$ & 3.7 & 96.3 & $\mathrm{NI}$ & NI & $>0.05$ \\
\hline Aypak et al. (45) & Turkey & 530 & $2-12$ & 33.6 & 66.4 & Yes & No & 0.000 \\
\hline Liao et al. (46) & China & 966 & $0.5-15$ & 11 & $89 \%$ & Yes & No & $<0.09$ \\
\hline
\end{tabular}

\footnotetext{
a Abbreviations: NI: Non identified.

b Mean age is equal to 12.5 .

c Data are presented as mean age.
} 
Rezaee R et al.

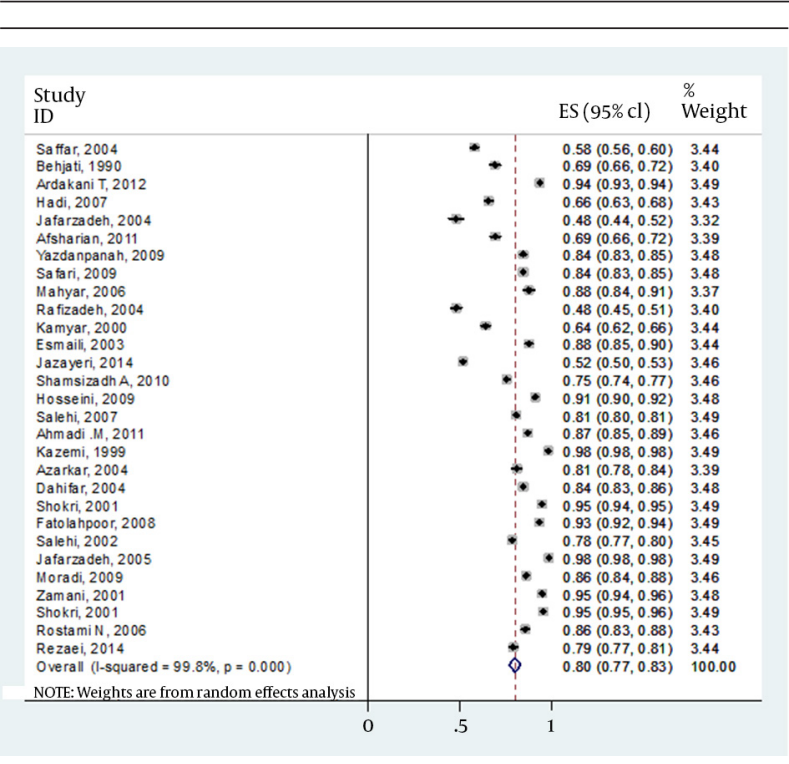

Figure 1. Forest Plot of Prevalence of HBV Vaccine Responsiveness in Iranian Whole Population

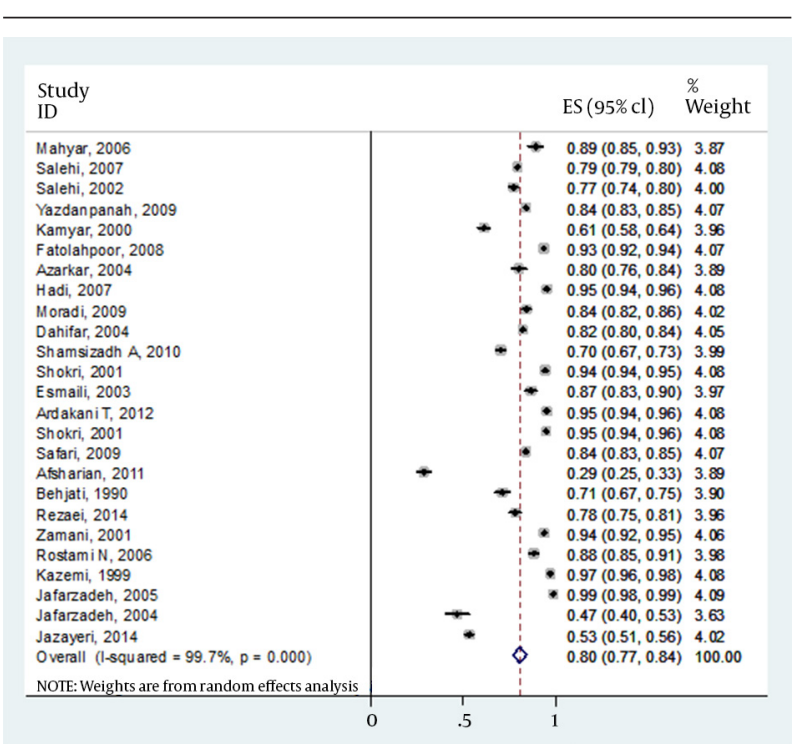

Figure 2. Forest Plot of Prevalence of HBV Vaccine Responsiveness in Iranian Male Population

\section{Discussion}

HBV Expanded program on immunization was started in Iran in 1993. Accordingly, more than $98 \%$ of infants have been vaccinated so far. There are ample data on the vaccine coverage rate, response to the vaccine, amnestic response to booster doses etc. among Iranian healthy children. However, no systematic review evaluated the levels of responsiveness to HBV vaccine. Moreover, most of those articles published in Persian language, makes the interpretation of data more incomprehensible. In this review, the impacts of different variables including age, gender, type of vaccine etc. on the rate of responsiveness were assessed statistically.

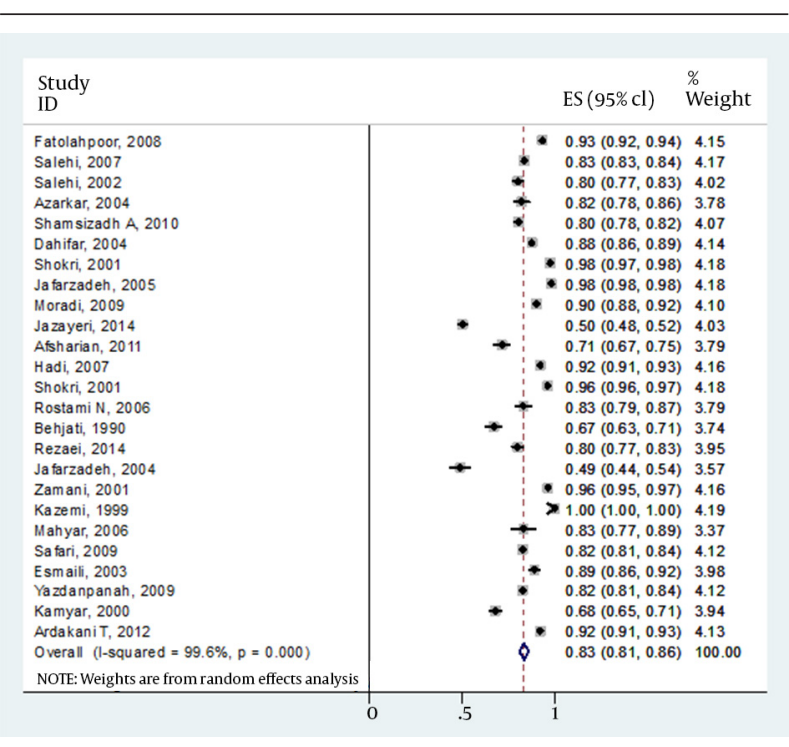

Figure 3. Forest Plot of Prevalence of HBV Vaccine Responsiveness in Iranian Female Population

Of 11639 children-studied, 9311 (80\%) and 2328 (20\%) were responders and nonresponders to vaccine, respectively. There have been numerous published data on the rate of response to $\mathrm{HBV}$ vaccine internationally; the reported rate of $\mathrm{HBV}$ vaccine responsiveness ranged between 41.6 and $98.3 \%$ (Table 4 ). The reverse was also realistic for the extreme of no responsiveness to vaccine. In Iran, the rate of responders to vaccine was between 47.6 and $98.3 \%$; however, in most studies (24 out of 28 papers, $85.7 \%$ ), responders were above $69 \%$ of population in the surveys.

Regarding the impact of age on the rate of response to vaccine, we did not find a significant difference between subjects, despite finding cut-off levels for anti-HBs between 500.95 and $164.82 \mathrm{IU} / \mathrm{mL}$ for those who were under three years old versus children more than three years old, respectively. However, this finding did not reach significance statistically. There are considerable variations between studies for association between the age of participants and response to vaccine. The massive gaps between the extreme of these results substantially correlated to the age of vaccines. For example, Table 4 shows that more increase in the age of vaccines, the more decline in the rate of responders. The other important issue is the timing between the last dose of vaccine administration and measurement of anti-HBs. Globally, in various reports, the age of children ranged between 5 and 15 years old; which makes substantial variance between the levels of anti-HBs in different age groups. On the other hand, this review and other studies showed that with increase in age, the number of nonresponders to vaccine increased significantly. Versatile ethnic groups, geographic variations, different age groups between subjects and difference in the endemicity of HBV in those areas might be the reasons for such discrepancies.

What is the impact of low level of anti-HBs on acquisition of HBV infection? Taken together, with exception of 
some rare reports on healthcare workers who were nonresponders to vaccine and subsequently infected with HBV (47-49), there is no data to support that after robust rising in anti-HBs following $\mathrm{HBV}$ vaccination, subsequent decrease in anti-HBs levels endanger the subject to HBV infection (50). Previous results showed that memory T cells maintain the response to the virus after encountering. This issue has been highlighted by the fact that after booster dose(s) of HBV vaccine in hypo/nonresponders, there has been amnestic response manifested by increase in the levels of anti-HBs $(45,51)$.

Interestingly, between years 1995 and 2014, there was no significant difference in the mean anti-HBs titers between Iranian studies $(\mathrm{P}=0.428)$. This finding together with this issue that the type of vaccine used did not show any significant differences between the rate of response to vaccine (P $>0.05$ ), indicate the reasonable potency and antigenicity of vaccine used in Iranian EPI, which were already assessed by our lab in vivo and in vitro studies $(52,53)$.

Despite some studies showed some differences in response to HBV vaccine between rural and urban areas (5457), we did not find any significant difference in Iranian publications. Furthermore, in our own yet unpublished study on 1200 samples from two categories of rural and urban districts, we did not find any considerable changes (Jazayeri's unpublished manuscript).

Overall, Iranian surveys did not find any significant correlation between gender of participants and the rate of response to vaccine $(\mathrm{P}=0.119)$, which was similar to other findings (Table 4 ).

Three studies evaluated HBsAg in children; the rate was between 0 and $1.29 \%$. Iran is considered as an intermediate area for HBsAg prevalence (2.54\%) (58). On the other hand, the rate of past $\mathrm{HBV}$ infection, manifested by anti-HBc, ranged between 0 and $7.7 \%$ in this review. Both relative high prevalence for $\mathrm{HBsAg}(4.6 \%)$ and anti-HBc $(7.7 \%)$ were reported exceptionally from Golestan and Kerman provinces. Previous reports showed rates of $6.3 \% \mathrm{HBsAg}$ and $8 \%$ anti-HBc in general population in these areas, respectively $(59,60)$. However, our unpublished data on 821 samples from vaccinated children showed no positive cases for both two markers (Jazayeri and Alavian, unpublished). Altogether, 0 to $1.29 \%$ prevalence of $\mathrm{HBsAg}$ together with 0 to $2.5 \%$ anti-HBc from different provinces underscored the usefulness of $\mathrm{HBV}$ vaccination for substantial reduction in HBV endemicity in Iran.

The results arose from this review highlighted special topics. First, in Iran, the vaccine was safe without considerable consequences. Second, the vaccine was effective in stimulating the immune response of vaccines reasonably, despite being different in generation, manufacturers and types. Third, there was no substantial difference between Iranian and other international investigations in the rate of nonresponsiveness to $\mathrm{HBV}$ vaccine.

\section{Acknowledgements}

The authors would like to express their gratitude to staff of the Virology department of Tehran University of Medical Sciences for their cooperation.

\section{Authors' Contributions}

Seyed Moayed Alavian and Seyed Mohammad Jazayeri: Study design. Reza Rezaee, Bahman Aghcheli and Vahdat Poortahmasebi: Date collection. Mostafa Qorbani: Statistical analysis.

\section{References}

1. Ding X, Yang Y, Han B, Du C, Xu N, Huang H, et al. Transcriptomic characterization of hepatocellular carcinoma with CTNNB1 mutation. PLoS One. 2014;9(5):e95307.

2. WHO. Geneva: 1991. Expanded programme on immunisation Report of 14th Global Advisory Group.

3. 3. Thomas HC., Lok A., Locarnini E., Zuckerman A. In: Variants of Hepatitis B Surface Antigen (HBsAg) 4 ed. Jazayeri SM, Alavian SM, Dindoost P, Thomas HC, Karayiannis P., editor. John Wiley \& Sons; 2014.pp. 107-26.

4. Zuckerman JN. Nonresponse to hepatitis B vaccines and the kinetics of anti-HBs production. J Med Virol.1996;50(4):283-8.

5. Milich DR, Leroux-Roels GG. Immunogenetics of the response to HBsAg vaccination. Autoimmun Rev. 2003;2(5):248-57.

6. Jilg W, Schmidt M, Deinhardt F. Four-year experience with a recombinant hepatitis B vaccine. Infection. 1989;17(2):70-6.

7. Chiara F, Bartolucci GB, Cattai M, Piazza A, Nicolli A, Buja A, et al. Hepatitis B vaccination of adolescents: significance of non-protective antibodies. Vaccine. 2013;32(1):62-8.

8. Are booster immunisations needed for lifelong hepatitis B immunity? European Consensus Group on Hepatitis B Immunity. Lancet. 2000;355(9203):561-5.

9. Saffar MI, Rezai MS. Long-term antibody response and immunologic memory in children immunized with hepatitis B vaccine at birth. Indian Pediatr. 2004;41(12):1232-7.

10. Behjati Ardakani M, Mir Hosseini NA, Ayatollahi J. [Survey of hepatitis B surface antigen titers in vaccinated 8 years old school children of Yazd]. Shahid Sadoughi Uni Med Sci And Health svc J. 2002; 10(3):3-7.

11. Taghavi Ardakani A, Soltani B, Sharif MR, Moosavi GA, Khademian M. [Evaluation of serum hepatitis B antibody level in vaccinated children after 14 years in Kashan, Iran.]. J Gorgan Univ Med Sci. 2012;14(3):104-8.

12. Hadi N, Hadi N. Assessment of anti-HBs antigen in 6- to 9-year-old children routinely vaccinated via vaccination program in Iran. Med Princ Pract. 2007;16(4):306-9.

13. Jafarzadeh A, Montazerifar SJ. Persistence of anti-HBs antibody and immunological memory in children vaccinated with hepatitis B vaccine at birth. J Ayub Med Coll Abbottabad. 2006;18(4):4-9.

14. Afsharian M, Ghaderi M, Vaziri S, Leghaei Z, Ghadiri K, Janbaksh A, et al. [Seroconversion rates after hepatitis-B vaccination in children].J Kermanshah Univ Med Sci. 2012;15(6):481-4.

15. Yazdanpanah B, Safari M, Yazdanpanah S. Persistence of HBV Vaccine's Protection and Response to Hepatitis B Booster Immunization in 5- to 7-Year-Old Children in the Kohgiloyeh and Boyerahmad Province, Iran. Hepat Mon. 2010;10(1):17-21.

16. Mahyar A. [Survey of Antibody Titers against Recombinant Hepatitis B Vaccination in 6 Years old Children].3. 2007;16 (61):39-43.

17. Rafizade B, Kazemi AN, Amir Moghadami HR, Moosavi Nasab N. [Survey of Anti-HBs Serum Level in Vaccinated 7-9 Year-old Children in Zanjan City 2004]. ZUMS J. 2004; 12(47) :49-55.

18. Mostafavi Zadeh K, Salehi H, Imani R, Haghayegh MR. [Antibody level against of hepatitis $B$ surface antigen after vaccination in children aged 5 to 6 years old after the newly school in the city shahrekord]. Res Med Sci. 2001; 6(3):194-196.

19. Esmaili M, Seyedkolal F. [Evaluation of anti HBS levels in vaccinated children against Hepatitis B, Amirkola Hospital, Babol] . KAUMS J ( FEYZ ). 2003; 6(4):45-49.

20. Shamsizadeh A, Makvandi M, Shoshtari G. Prevalence of anti hepatitis B surface antibody among children in Ahvaz, Iran, five 
years after vaccination. Jundishapur J Microbiol. 2011;4(1):e2592.

21. Hosseini SM, Ranjbar R, Abolghasemi H, Turkaman M. Evaluation of the Level of HBV Antibody Titer after HBV Vaccination among Children in Tehran, Iran. Hepat Mon. 2009;9(2):150-3.

22. Salehi H, Farajzadegan Z. Antibody titer in Iranian children 6 years after hepatitis B vaccine administration. Vaccine 2007;25(17):3511-4.

23. Ahmadi M, Moosavi SM, Jahanfar F. [Comparison of antibody level in post hepatitis B vaccination in children with 12-15 and 21-24 months age]. J Gorgan Univ Med Sci. 2012;14(2):59-65.

24. Kazemi A, Koosha A, Rafizadeh B, Mousavinasab N, Mahram M. Serum level of anti-hepatitis B surface antigen 6-8 years after hepatitis B vaccination at birth. East Mediterr Health J. 2008;14(4):960-5.

25. Azarkar Z. [Efficacy of hepatitis B vaccine in children from 12 to 16 months in Mashad health centers]. J Qazvin Univ of Med Sci. 2004;7(5):38-41.

26. Dahifar H. Immunogenicity of Cuban hepatitis B vaccine in Iranian children. Arch Iranian Med. 2004;7(2):89-92.

27. Jafarzadeh A, Khoshnoodi J, Ghorbani S, Hazrati SM, Mazaheri BF, Shokri F. Differential Immunogenicity of A Recombinant Hepatitis B Vaccine in Iranian Neonates: Influence of Ethnicity and Environmental Factors. Int J Infect. 2004;1(2):98.

28. Fatolah Poor A, Hematpoor S, Ghaderi E. Effect of hepatitis B vaccination in children vaccinated between 12 and 24 months old city of Sanandaj. Journal of Infectious Diseases. 2008;41(1):65-70.

29. Salehi M, Sanei Moghadam E, Khosravi S. [Evaluation of immune response of Hepatitis B vaccination in Zahedan infants]. Zahedan J Res Med Sci. 2002;4(3):155-8.

30. Moradi A. [The response rate to hepatitis B vaccination in children younger than one year of Gorgan]. J Gorgan Univ Med Sci. 2008;10(2):50-5.

31. Zamani A, Shajari H, Sedighy I. Study On The Ef Ficacy Of Recom binant Hepatitis B Vaccine In Iranian Infants. Med J Islamic Repub Iran. 2001;14(4):347-9.

32. Shokri F, Jafarzadeh A. High seroprotection rate induced by low doses of a recombinant hepatitis B vaccine in healthy Iranian neonates. Vaccine. 2001;19(31):4544-8.

33. Rostami N, Ghaffari V, Samaie H. Comparison of Immune Response to Hepatitis B Vaccine Between Term and Preterm Infants at Birth. Arch Clin Infect Dis. 2006;7(1):11-4.

34. Rezaei M, Nooripoor S, Ghorbani R, Ramezan Shams F, Mamishi $\mathrm{S}$, Mahmoudi S. Seroprotection after hepatitis B vaccination in children aged 1 to 15 years in central province of Iran, Semnan. prev med hyg. 2014;55(1):1-3.

35. Elian F, Shubair M. Evaluation of the efficacy of Hepatitis B vaccine in different age groups of immunized children in Gaza strip. Islamic Univ J. 2006;14(1):91-103.

36. Livramento A, Cordova CM, Scaraveli NG, Tonial GC, Spada C, Treitinger A. Anti-HBs levels among children and adolescents with complete immunization schedule against hepatitis B virus. A cross-sectional study in Blumenau, State of Santa Catarina, Brazil, 2007-2008. Rev Soc Bras Med Trop. 2011;44(4):412-5.

37. Madour A, Alkout A, Vanin S. First evaluation of the serum level of anti-hepatitis B surface antigen after vaccination in Libya. East Mediterr Health J. 2013;19(12):990-4.

38. Zanetti AR, Mariano A, Romano L, D'Amelio R, Chironna M, Coppola RC, et al. Long-term immunogenicity of hepatitis B vaccination and policy for booster: an Italian multicentre study. Lancet 2005;366(9494):1379-84.

39. Dong Y, Liu SL, Zhai XJ, Zhu FC, Pan H, Yu JX, et al. A serological and molecular survey of hepatitis B in children 15 years after inception of the national hepatitis B vaccination program in eastern China. J Med Virol. 2009;81(9):1517-24.

40. Sallam TA, Alghshm HM, Ablohom AA, Alarosi MS, Almotawake $\mathrm{RE}$, Farea $\mathrm{NH}$, et al. Immune response to Hepatitis B vaccine among children in Yemen. Saudi Med J. 2005;26(2):281-4

41. Belloni C, Chirico G, Pistorio A, Orsolini P, Tinelli C, Rondini G Immunogenicity of hepatitis $B$ vaccine in term and preterm in- fants. Acta Paediatr. 1998;87(3):336-8.

42. Hwang LY, Beasley RP, Stevens CE, Szmuness W. Immunogenicity of $\mathrm{HBV}$ vaccine in healthy Chinese children. Vaccine. 1983;1(1):10-2.

43. Chongsrisawat V, Yoocharoen P, Theamboonlers A, Tharmaphornpilas P, Warinsathien P, Sinlaparatsamee S, et al. Hepatitis B seroprevalence in Thailand: 12 years after hepatitis B vaccine integration into the national expanded programme on immunization. Trop Med Int Health. 2006;11(10):1496-502.

44. Sadeck LS, Ramos JL. [Immune response of preterm infants to hepatitis B vaccine administered within 24 hours after birth]. Pediatr (Rio J). 2004;80(2):113-8.

45. Aypak C, Yuce A, Yikilkan H, Gorpelioglu S. Persistence of protection of hepatitis B vaccine and response to booster immunization in 2- to 12-year-old children. Eur J Pediatr. 2012;171(12):1761-6.

46. Liao SS, Li RC, Li H, Yang JY, Zeng XJ, Gong J, et al. Long-term ef ficacy of plasma-derived hepatitis B vaccine: a 15-year follow-up study among Chinese children. Vaccine. 1999;17(20-21):2661-6.

47. McMahon BJ, Bruden DL, Petersen KM, Bulkow LR, Parkinson AJ, Nainan O, et al. Antibody levels and protection after hepatitis B vaccination: results of a 15-year follow-up. Ann Intern Med. 2005;142(5):333-41.

48. Hofmann F, Kralj N. Criteria for successful hepatitis B vaccination in adults: results of a case study. Infection. 2009;37(3):266-9.

49. Boot HJ, van der Waaij LA, Schirm J, Kallenberg CG, van Steenbergen J, Wolters B. Acute hepatitis B in a healthcare worker: a case report of genuine vaccination failure. J Hepatol. 2009;50(2):426-31.

50. Rosenberg C, Bovin NV, Bram LV, Flyvbjerg E, Erlandsen M, VorupJensen T, et al. Age is an important determinant in humoral and T cell responses to immunization with hepatitis B surface antigen. Hum Vaccin Immunother. 2013;9(7):1466-76.

51. do Livramento A, Schultz J, Batista KZ, Treitinger A, de Cordova $\mathrm{CM}$, Spada C. Immune memory response induced in vitro by recombinant hepatitis B surface antigen challenge 13-18 years after primary vaccination. J Med Virol. 2014;86(10):1700-4

52. Karimzadeh H, Pakzad SR, Mahmoudi M, Ajdary S, Norouzi M, Akbari M. [Set up of analytical methods for evaluation of specifications of recombinant Hepatitis-B vaccine]. Tehran Unive Med Sci. 2009;67(3)

53. Karimzadeh H, Ajdary S, Jazayeri SM, Pakzad SR. Validation of an in-vitro method for Hepatitis B vaccine potency assay: specification setting. Panminerva Med. 2010;52(3):177-82.

54. Davaalkham D, Ojima T, Wiersma S, Lkhagvasuren T, Nymadawa $\mathrm{P}$, Uehara R, et al. Administration of hepatitis B vaccine in winter as a significant predictor of the poor effectiveness of vaccination in rural Mongolia: evidence from a nationwide survey. J Epidemiol Community Health. 2007;61(7):578-84.

55. de la Hoz F, Perez L, de Neira M, Hall AJ. Eight years of hepatitis B vaccination in Colombia with a recombinant vaccine: factors influencing hepatitis B virus infection and effectiveness. Int J Infect Dis. 2008;12(2):183-9.

56. De La Hoz F, Hall AJ. . Hepatitis B Vaccination In The Colombian Amazon Effectiveness And Factors Influencing Vaccination Coverage. London: University of London; 2002.

57. Liang X, Bi S, Yang W, Wang L, Cui G, Cui F, et al. Evaluation of the impact of hepatitis B vaccination among children born during 1992-2005 in China. JInfect Dis. 2009;200(1):39-47.

58. Alavian SM, Fallahian F, Lankarani KB. The changing epidemiology of viral hepatitis B in Iran. $J$ Gastrointestin Liver Dis. 2007;16(4):403-6.

59. Alavian SM, Hajarizadeh B, -Asl MA, Kabir A, Lankarani KB. Hepatitis B Virus Infection in Iran: A Systematic Review. Hepat Mon. 2008;8(4):281-94.

60. Delavari M, Shahabinejhad N, Renzaho A, Zahedi M, Owhadi AR Frequency of Anti-HBc \& HBV DNA detection in blood donors of Kerman province, Iran.J Blood Disord Transfus. 2011;2(1):1-4 